\title{
The Past, Present, and Future of Progress
}

M. O. Lozano-Justice

Correspondence | molj3170@gmail.com

Citation | Lozano-Justice, M. O. 2019. “The Past, Present, and Future of Progress.” Journal of Big History, IV (1): 69-72. http://dx.doi.org/10.22339/jbh.v4i1.4140.

DOI | http://dx.doi.org/10.22339/jbh.v4i1.4140

The conquest of the earth, which mostly means the taking it away from those who have a different complexion or slightly flatter noses than ourselves, is not a pretty thing when you look into it too much. What redeems it is the idea only. An idea at the back of it; not a sentimental pretense but an idea; and an unselfish belief in the idea-something you can set up, and bow down before, and offer sacrifice to [....]" - Joseph Conrad (Heart of Darkness)

"The story of human progress is truly heroic. It is glorious. It is uplifting. It is even, I daresay, spiritual." -Steven Pinker (Enlightenment Now)

"[I]f you dream of a society in which truth reigns supreme and myths are ignored, you have little to expect from Homo Sapiens. Better to try your luck with chimps."-Yuval Noah Harari (21 Lessons for the 21st Century)

At a time when anger and anomie appear to be the order of the day, and the ideals of the Enlightenment are being bombarded from every direction, Yuval Noah Harari and Steven Pinker have entered the fray once more to remind us that all is not lost and to ensure us that reports of the death of liberalism are greatly exaggerated. Taken together, Pinker and Harari, in their most recent books, offer a calculated and compelling assessment of how far humanity has come as a species and where we should look to go in the future. In Enlightenment Now: The Case for Reason, Science, Humanism, and Progress, Pinker contends that now, more than ever, as the dominant narrative has become that of a deepening global crisis and the failure of modernity, classical liberalism needs a forceful and steadfast defense. Using a bewildering amount of data that are neatly broken down into digestible graphs, Pinker is able to argue convincingly that not only has the En- lightenment project worked reasonably well but that when properly appreciated, "the ideals of the Enlightenment are, in fact, stirring, inspiring, noble-a reason to live" (Pinker 6). Harari's 21 Lessons for the 21st Century picks up at the point where Pinker leaves off. After establishing early in his book that liberalism is (as Pinker also contends), "the most successful and most versatile political model humans have so far developed for dealing with the challenges of the modern world" (Harari xviii), Harari then looks to the immediate future and asks whether the ideals of the Enlightenment will be enough to deal with the oncoming revolutions in information technology and biotechnology. He maintains that in the next few decades humankind will be confronted with the most challenging dilemma we have ever faced. If liberalism wishes to survive in a world where infotech and biotech collide, it will have to adjust and reinvent itself once again.
Both men agree that we are living at a time when it is difficult "to find meaning and purpose if traditional religious beliefs about an immortal soul are undermined by our best science" (Pinker 3) and that we are, therefore, "left with the task of creating an updated story of the world" (Harari 16). In a world where many exhibit "an inability to conceive of a higher purpose in anything other than religion," and where "cynicism about the institutions of modernity" (Pinker xv) has become the norm, how will this new story go? Is a new, captivating, and unified narrative even necessary- or desirable? Harari, for one, is unequivocal on the matter: "If this generation lacks a comprehensive view of the cosmos, the future of life will be decided at random" (Harari 266). Although Pinker and Harari do agree on much and more, they also have their points of disagreement. In fact, they are somewhat reminiscent of Pestov and Sergey Ivanovich at one of 
Stiva's parties in Anna Karenina. "Both [are] men respected for their character and their intelligence" but are in marked disagreement on several subjects, "not because they belong to opposite parties, but precisely because they [are] of the same party," where "each has his own special shade of opinion." However, at this party, the task of "jeering without anger" at their "incorrigible aberrations" will fall to me.

In two early chapters titled "Counter-Enlightenments" and "Progressophobia," Pinker takes aim at the academic pessimism that has infiltrated and spread throughout universities-in particular, the Arts and $\mathrm{Hu}$ manities departments. Pinker venomously attacks everyone from the Romantics and Rousseau to Fanon and Foucault-with a particular rancor reserved for Nietzsche-and urges us to abandon these thinkers with their emphasis on the shortcomings of modernity in favor of those who extol the vir- tues and values of the Enlightenment. As Pinker rightly asserts, it is these masters of suspicion, or as he disparagingly calls them, "prophets of doom," who have become the rock stars of the liberal arts curriculum. Where Pinker is on weaker footing is in his tacit assertion that we would all be better off if these men never existed. In one passage (penned with palpable vitriol and bitterness), Pinker defends the Enlightenment project against charges that it is a Western creation that refuses to account for the great diversity of thought throughout the world and, therefore, is unsuited to deal with all the world's problems. While refuting the charges that "the Enlightenment is the guiding ideal of the West," Pinker tellingly responds, "If only!" before going on a twochapter tirade against any intellectual tradition that does not fall within the purview of the Enlightenment. This line of thinking is shortsighted and problematic for several reasons-many of which Harari directly addresses.

To Pinker's charge that universities have become infested with a pessimistic frame of mind and that there is a dire need to change this outlook to a more optimistic one, Harari offers a simple and straightforward explanation. In the book's introduction, while detailing his reasoning for writing the book in the manner in which he does (focusing on the shortcomings of modernity and the liberal worldview), Harari states that "I do so not because I believe liberal democracy is uniquely problematic but rather because I think it is the most successful and most versatile political model humans have so far developed [. . .]" and that, moreover, "[w]ithout criticizing the liberal model, we cannot repair its faults or move beyond it" (Harari xviii-xix). Put differently, progress does not happen and has never happened by praising how great and perfect the world is but rather by recognizing and criticizing our flaws in order
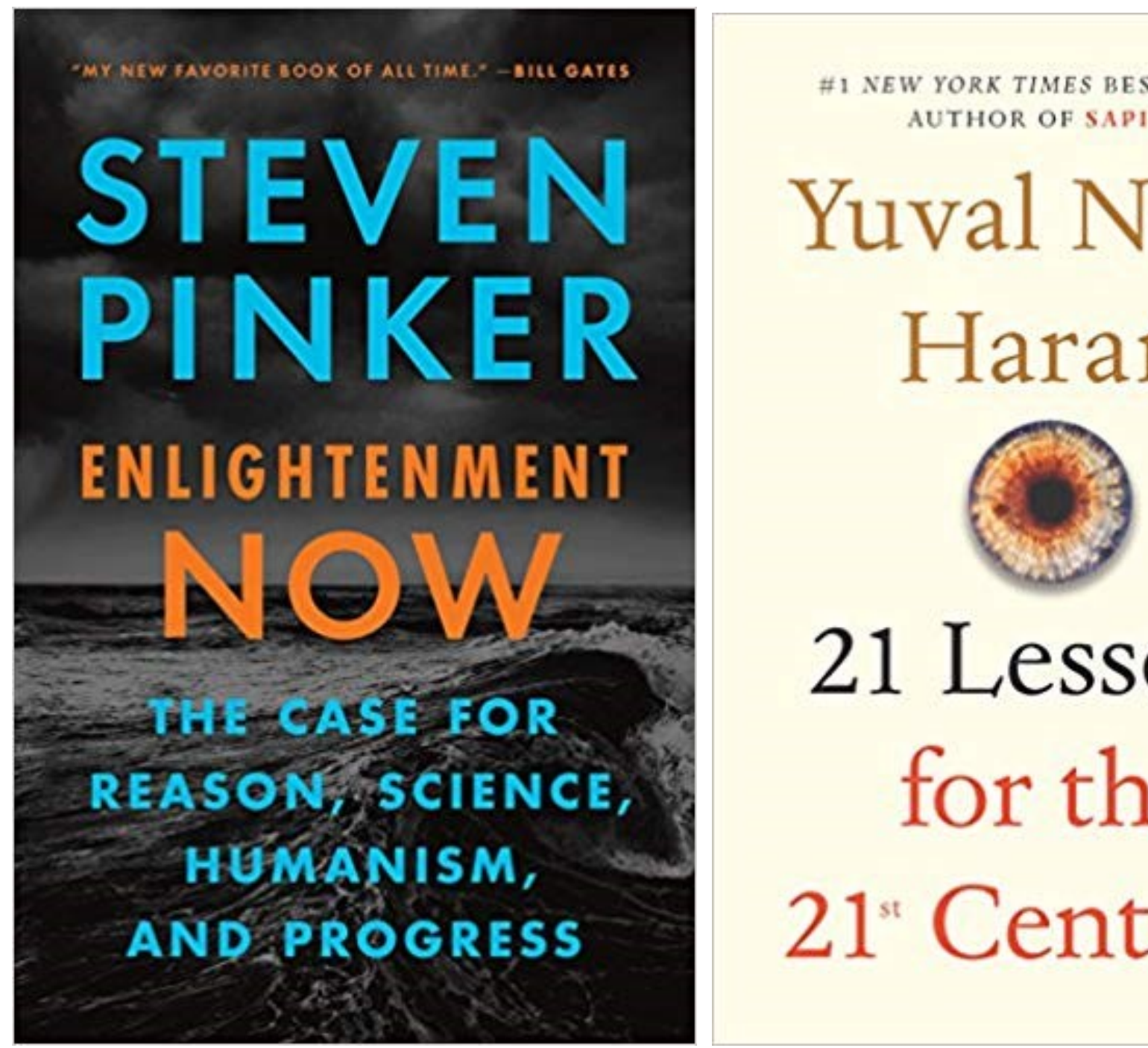

21 Lessons
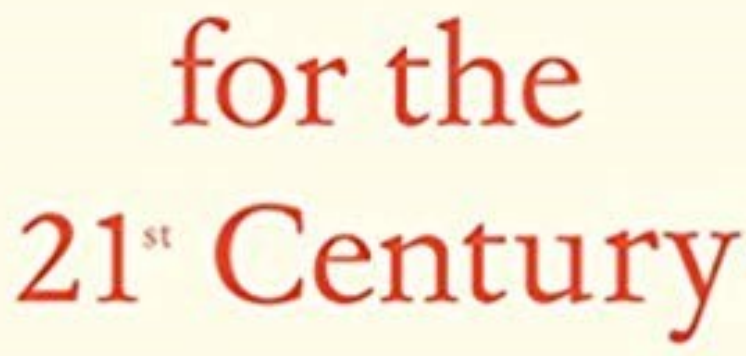
to improve them. This is an obvious point that Pinker not so much ignores; instead, he seems to view as a useful tool of a bygone era, yet it is no longer applicable to our modern world ruled by the self-correcting procedures of science and reason. In a quite frankly shocking display of presentism, Pinker praises the "muckraking journalists and novelists like Upton Sinclair" (Pinker 186) for propelling progress during the early 2oth century while simultaneously bemoaning the fact that in recent years works on topics such as genocide, terrorism, cancer, and racism have received major literary prizes as works on progress have been given short-shrift. In a book about progress, this blatant disregard for how progress continues to work is troublesome.

Moreover, throughout the book, Pinker showcases a surprising display of bad intellectual history that I can only assume is used intentionally to bolster his argument. For instance, in a percipient paragraph discussing "scientific racism," which reached peak popularity in the late nineteenth and early twentieth centuries, Pinker correctly concludes that "[y]et to pin ideological racism on science [. . .] is bad intellectual history" (Pinker 397). Although his statement is $100 \%$ correct, the problem arises when Pinker then turns around and participates in this same bad intellectual history by blaming all of modernity's ills on the counter-enlightenment thinkers and progressophobes. To display such a concise and cogent understanding in the one case only to turn around and commit the same errors is a baffling showcase of willful ignorance and intellectual dishonesty.

As perplexing as Pinker's reasoning is in the matter, it may have its roots in something Harari directly confronts in a particularly insightful chapter titled "Post-Truth: Some Fake News Lasts Forever.” After succinctly explaining that humans have always lived in an age of post-truth because Homo sapiens is a post-truth species, Harari moves on to a discussion on truth vs. power. As he masterfully details, truth and power have always been mostly incompatible and can travel only so far together before they are forced to go their separate ways. This is not a new discovery but rather a dilemma that scholars are aware of and have been wrestling with for hundreds of years. If you want a powerful story, you have to invent fictions; on the flip-side of that, if you want a truthful story at some point, you will have to renounce power. When sitting down to write, scholars have to ask themselves, "Do they serve truth or power? Should they aim to unite people by making sure everyone believes in the same story, or should they let people know the truth even at the price of disunity?" (Harari 247) Some of the most successful scholars and all of the most powerful narratives throughout history have valued unity over truth - in part because they understand that humans as a species prefer power to truth. When writing his book, Pinker was faced with this same dilemma, and at times (though indeed not always), he chooses to sacrifice truth on the altar of power.

Before this runs the risk of reading as a full-on diatribe against Pinker, it must be stated that Enlightenment Now is a thoroughly engaging and invaluable read that gets much more right than it does wrong. One of the stronger points of the book comes when Pinker details how the Optimism Gap combines with the Availability Heuristic to form a bias toward negativity, which is further reinforced by the daily news cycles to form a distorted view of reality that convinces us that the world is all going to pot. Other strong chapters include his chapters titled "Terrorism" and "Science." In the former chapter, Pinker reminds us (through data, as is his forte) that the very nature and design of terrorism is to create an outsized panic by combining major dread with minor harm. While in the latter chapter, Pinker's coverage of C. P. Snow and Snow's advocation of a "Third Culture" going forward is particularly refreshing. In his chapter, "Democracy," Pinker shines when discussing what he aptly refers to as our civics-class idealization of democracy and makes the compelling case that throughout history, peo- ple have always voted with their hearts and not their minds. However, what Pinker does best in his book (sometimes subtly, other times heavyhandedly) is to remind us that it is the very "nature of progress that it erases its tracks, and its champions fixate on the remaining injustices and forget how far we have come" (Pinker 215). It is this last profound point of Pinker's, which he underscores throughout, that brings me to my final critique.

Throughout his book, Pinker is able to make a compelling case for progress in large part because he takes a long-durée view of history. Pinker is correct that if we take a broad view of history as opposed to a narrow one, what we begin to see is a more progressive and optimistic trajectory of history. However, it is equally important to keep in mind that we should never replace wholesale one view for the other. It can be extremely dangerous and misleading to emphasize long-term progress at the cost of short-term atrocities. Doing so can make indefensible inhumanities seem like right actions justified through the name of progress. Although it can be easy to agree with Pinker that we live at a time when progress needs a determined defense, it is vital that this defense must not turn into a fetishization of progress.

So, now that we have been dually introduced to both the self-eradicating nature of progress and the dangers in fetishizing progress-what does the future of progress look like? As Harari points out, we find ourselves living in an age of bewilderment where simultaneously the credibility of liberalism is being questioned, and the twin revolutions in information technology and biotechnology are confronting us head-on and threatening to reshape the world as we know it. In such a time of uncertainty, one cannot be faulted for calling into question the progressive projection of history and wondering what the future will hold. Questions such as "Who are we? What should we do in life? What kinds of skills do we need? Given everything we know and don't know about science, about God, about politics, and 
about religion, what can we say about the meaning of life today?" (Harari xviii) require fresh answers in an era of looming ecological crisis and the growing threat of weapons of mass destruction. Add to the mix the fact that the revolutions in infotech and biotech are "giving humanity the power to reshape and reengineer life" (Harari xviii), and these questions become even more pressing. As Harari concludes, nothing is more crucial in an age of bewilderment than self-observation and self-knowledge. In the penultimate chapter of 21 Lessons titled "Meaning: Life Is Not a Story," Harari underscores the vital importance of understanding ourselves. As he states, "in order to understand ourselves, a crucial step is to acknowledge that the 'self' is a fictional story that the intricate mechanisms of our mind constantly manufacture, update, and rewrite" (Harari 305). This story that we tell ourselves, about ourselves, often bears little resemblance to reality, and the vast majority of our experiences never enter into the narrative of the in- ner self that we choose to create. As misleading and false as the stories of ourselves are, they nevertheless provide us with explanations to the questions of who we are; where we come from; and where we should look to go. However, as Harari eloquently explains: if you really want to understand yourself, "The first thing you need to know about yourself is that you are not a story" (Harari 306), and that we should cease to identify with these sanitized and fictitious inner narratives with which we choose to delude ourselves. In the immediate future, selfobservation and self-knowledge will be paramount, for "Unless you are happy to entrust the future of life to the mercy of quarterly revenue reports, you need a clear idea of what life is all about" (Harari xviii).

Although Pinker offers an optimistic take on our past and present and Harari takes a more tempered and pessimistic approach to our immediate future, taken together, Enlightenment Now and 21 Lessons for the 21st Century offer a sobering, cal- culated, and thoroughly researched assessment of the state of the world and should be given a serious look by anyone concerned with the contemporary story of who we are, where we come from, and where we should look to head in the immediate future.

\section{References}

Harari, Yuval Noah. 21 Lessons for the 21st Century. New York: Spiegel \& Grau, 2018.

Pinker, Steven. Enlightenment Now: The Case for Reason, Science, Humanism, and Progress. New York: Penguin Books, 2018. 